\title{
Puumelassi tuoreviljan säilöntäaineena
}

\author{
Maija-LiIsa Salo \\ Helsingin yliopiston kotieläintieteen laitos, 00710 Helsinki 71
}

\section{Wood molasse as a preservative for high-moisture grains}

Maija-Lissa Salo

Department of Animal Husbandry, University of Helsinki, 00710 Helsinki 71

\begin{abstract}
An unneutralized $(\mathrm{pH}$ 2) low-lignosulphonate wood molasse from spent sulphite liquor (58 \% DM) was tested on a laboratory scale for wet preservation of ground barley, oats and Brewers' grains. 10 and $20 \%$ of wood molasse of the dry matter of grains prevented faulty fermentation in a warm storehouse. Also the lactic acid fermentation remained slight, because even $10 \%$ wood molasse addition lowered the reaction to under $\mathrm{pH} 5$.

The growth of mould was diminished by wood molasse only by using large concentrations and a cold warehouse. Therefore it had hardly any benefit in the preservation of whole high-moisture grains.

The low-lignosulphonate wood molasse was more palatable than the earlier tested high-lignosulphonate sulphite spent liquor.
\end{abstract}

\section{Johdanto}

Vilja on viime vuosikymmenelle asti käsitelty varastoimiskelpoiseksi lähes yksinomaan kuivaamalla. Kustannustason alkaessa jyrkästi nousta on rehuksi tarkoitetun viljan säilytykseen alettu kokeilla kuivaamista halvempia vaihtoehtoja. Niistä tunnetuin on propionihapposäilöntä. Muurahais- ja etikkahappoakin voidaan käyttää, mutta ne ovat propionihappoa epävarmempia.

Uusia tulokkaita ovat ammoniakki (Bothast ym. 1975) ja niinikään ammoniakkivaikutukseen perustuva urea (SснміDт vm. 1978). Sekä edellämainitut hapot että ammoniakki ovat tehokkaita fungisideja ja estävät siten myös viljan aerobin pilaantumisen.

Vajaatuleentuneena ja kosteana korjatun viljan säilöntään on jo pitkään käytetty märkä- eli murskesäilöntää. Siinä murskattuun märkään viljaan sekoitetaan nurmisäilörehujen säilöntäainetta ja vilja pakataan siiloon ilmanpitävästi. Tämä säilöntämuoto ei estä aerobia mikrobitoimintaa, vaan avoin pinta homehtuu herkästi. 
Tässä tutkimuksessa säilöntäaineeksi kokeiltiin neutraloimatonta puumelassia, samantapaista ainetta mitä on käytetty märehtijäin rehuksi (HATHAwAY 1973, Salo ym. 1973, Chang ym. 1977). Kokeet suoritettiin vasta laboratoriomittakaavassa ja ne käsittivät jauhetun viljan ja tuoreen mäskin märkäsäilönnän ja ohran ja kauran jyväsäilönnän.

\section{Aineisto ja menetelmät}

Puumelassi oli Oy Serlachius Ab:n tehtaalta, alkuperältään koivupuun selluloosakeiton jäteliemen jalostetta tiivistettynä noin $55 \%$ :n kuiva-ainepitoisuuteen. Aikaisemmin tutkitusta sulfiittiliemestä (SALo ja PUUmala 1978) se poikkesi monessa suhteessa: Se oli hapanta ja sen vuoksi vesimäisen juoksevaa. Propionihappoa oli runsaasti ja etikkahappoa hyvin vähän. Lignosulfaateista oli ultrasuodatuksella poistettu noin kaksi kolmannesta. Puumelassin tärkeimmät koostumustiedot esitetään taulukossa 1 .

Taulukko 1. Ultrasuodatetun puumelassin koostumus.

Table 1. Composition of the ultrafiltrated spent sulphite liquor.

\begin{tabular}{|c|c|}
\hline 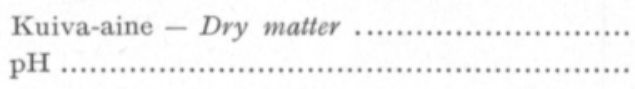 & $\begin{array}{c}58 \% \\
2\end{array}$ \\
\hline ka:sta $-\%$ of $D M$ & \\
\hline okeri - Sugars $^{1}$ ) ...... & $52 \%$ \\
\hline okerihapot - Sugar acids ......................... & 5 \\
\hline tikkahappo - Acetic acid $. . . \ldots \ldots \ldots \ldots \ldots \ldots . . . . . . . . .$. & 1 \\
\hline ropionihappo - Propionic acid ................. & 10 \\
\hline ignosulfonaatit - Lignosulphonates ..... & 15 \\
\hline Rikki - Sulphur $\left.{ }^{2}\right)$.................... & 3 \\
\hline uhka $-A s h .$. & 6 \\
\hline
\end{tabular}

1) Noin $70 \%$ sokereista on ksyloosia - Xylose forms ca. $70 \%$ of the sugars

${ }^{2}$ Lignosulfonaatteihin sidottua - Bound to lignosulphonates.

Ohra ja kaura jouduttiin kokeisiin kostuttamaan, koska puumelassi saatiin vasta niin myöhään syksyllä, että vilja oli jo kuivattu. Ohranmäski käytettiin kokeisiin heti tuoreena.

\section{Märkäsäilöntä}

Karkeaksi jauhettuun viljaan lisättiin vettä niin paljon, että kosteudeksi tuli noin $50 \%$, sekä jätemelassia 0,5 tai $10 \%$ (0, 10 tai $20 \%$ ka:sta). Seokset painettiin tiiviisti 1-1 1/2 litran lasitölkkeihin, pinta peitettiin löyhästi muovikalvolla ja päälle pantiin kevyt paino. Tölkit vietiin pimeään varastoon, minkä lämpötila oli noin $+16^{\circ} \mathrm{C}$.

Tuore mäski, mikä sisälsi vain $20 \%$ kuiva-ainetta, käsiteltiin samalla tavalla. Puumelassia lisättiin $0,2,4$ tai $6 \%$ tuoreesta $(0,10,20$ tai $30 \%$ ka:sta). Yhdet näytepurkit säilytettiin lämpimässä $\left(+16^{\circ} \mathrm{C}\right)$ ja toiset kylmässä $\left(+4^{\circ} \mathrm{C}\right)$ varastossa. 


\section{Jyväsäilöntä}

Ohran ja kauran jyviin lisättiin vettä niin paljon, että kosteudeksi tulı noin $30 \%$ ja jyvien annettiin kostua suljetussa astiassa kylmässä varastossa $\left(+4^{\circ} \mathrm{C}\right)$ neljän viikon ajan. Jyvät turposivat, mutta eivät homehtuneet. Sitten niihin sekoitettiin puumelassia 0, 5 tai $10 \%$ tuorepainosta. Koejyvät säilytettiin löyhästi muovikalvolla peitetyissä muovitölkeissä, toiset erät lämpimässä toiset kylmässä varastossa.

Koeastioita tarkkailtiin viikottain ja kokeen päättyessä märkäsäilötyistä tehtiin aistivaraisten havaintojen lisäksi taulukossa 2 esitetyt määritykset. Menetelmät olivat samat, mitä on käytetty säilörehuilla (ETTALA ym. 1972).

\section{Tulokset ja tarkastelu}

\section{Märkäsäilöntä}

Lämpimässä varastossa 0-näytteiden ja kauralla sekä mäskillä myös koenäytteiden avoimeen pintaan muodostui hometta, runsaasti puumelassia sisältäviin kuitenkin muita hitammin ja vähemmän. Ohralla koenäytteet poikkesivat muista: pinta vähän tummui, mutta ei homehtunut. 0-näytteissä koko massa alkoi vähitellen tummua pinnasta pohjaa kohden. Mäskistä oli rinnakkaisnäytteet kylmässä varastossa ja niihin muodostui hometta vasta noin puolentoista kuukauden säilytysajan jälkeen.

Kaikki lämpimän varaston näytteet analysoitiin samalla kertaa. Tölkkien pinnasta kuorittiin aerobisti pilaantunut kerros pois, viljoilla noin $2 \mathrm{~cm}$, mäskillä $4 \mathrm{~cm}$ ja loppu sekoitettiin analyysejä varten.

Aistivaraisesti voitiin todeta, että 0 -näytteissä oli voimakas mädänneen haju. Väriltään ne olivat puumelassia sisältäviä näytteitä sameampia, viljat myös tummempia. Kaikissa jätemelassia sisältävissä näytteissä oli melassin määrästä riippumatta vain mieto hapan haju.

pH-määritys osoitti, että neutraloimaton jätemelassi on niin hapanta, että jo $10 \%$ :n lisäys kuiva-aineesta laskee $\mathrm{pH}: \mathrm{n}$ alle viiden. Osa happamista aineista on säilöntäaineina tehokkaaksi tunnettua propioni- ja etikkahappoa, osa lignosulfonihappoja ja kalsiumbisulfiittia.

Alkuhappamuuden vuoksi maitohappokäyminen lämpimässäkin varastossa jäi vähäiseksi. Myös virhekäyminen estyi, kuten raikas haju ja analyysitulokset (taulukko 2) osoittivat. Avoimen pinnan pilaantumista puumelassi sen sijaan ei ainakaan lämpimässä varastossa estänyt, tosin sitäkin suurena konsentraationa hillitsi. Eri materiaaleilla oli tässä kohden eroa: ohraan ei tullut hometta lainkaan, mäskiin tuli nopeimmin ja eniten.

Koska säilyminen tapahtui pääasiassa puumelassin ja vain pienessä määrin käymisen ansiosta, jäi käymishappojen ja ammonium-typen määrä vähäisemmäksi, mitä tuoreohraa tavanomaisilla säilöntäaineilla säilöttäessä on todettu, vaikka säilytyspaikka silloin on ollut viileä (Poutiainen ym. 1973). Tämän kokeen koenäytteiden propioni- ja etikkahappo oli lisäksi suurelta osin peräisin lisätystä puumelassista. 
Taulukko 2. Puumelassilla (pH 2) märkäsäilötyn jauhetun viljan ja mäskin koostumus.

Table 2. The composition of wet ground grains and Brewers' grains preserved with wood molasse ( $p H$ 2).

\begin{tabular}{|c|c|c|c|c|c|c|c|c|c|c|c|}
\hline \multirow{2}{*}{$\begin{array}{c}\text { Wood } \\
\% \\
\text { of wet } \\
\text { weight }\end{array}$} & \multirow{2}{*}{$\begin{array}{r}\frac{\text { molasse }}{\%} \\
\text { of } \stackrel{\mathrm{DM}}{ }\end{array}$} & \multirow{2}{*}{$\begin{array}{c}\text { Preservation } \\
\text { period } \\
\text { days }\end{array}$} & \multirow{2}{*}{$\begin{array}{c}\text { Dry } \\
\text { matter } \\
\%\end{array}$} & \multicolumn{2}{|c|}{$\mathrm{pH}$} & \multicolumn{4}{|c|}{ Acids \% of DM } & \multicolumn{2}{|c|}{$\%$ of total nitrogen } \\
\hline & & & & $\begin{array}{l}\text { begin- } \\
\text { ning }\end{array}$ & end & lactic & acetic & $\begin{array}{l}\text { propio- } \\
\text { nic }\end{array}$ & butyric & $\mathrm{NH}_{3}-\mathrm{N}$ & $\begin{array}{l}\text { water- } \\
\text { soluble } \\
\text { N }\end{array}$ \\
\hline Ohra & Barley & 130 & & & & & & & & & \\
\hline 0 & 0 & & 48 & 5,7 & 4,1 & 3,6 & 0,54 & 0,27 & & 5,8 & 56 \\
\hline 5 & 10 & & 51 & 4,5 & 4,4 & 0,8 & 0,22 & 0,22 & & 2,8 & 45 \\
\hline 10 & 20 & & 50 & 4,1 & 4,1 & 0,3 & 0,25 & 0,45 & & 1,8 & 41 \\
\hline Kaura & Oat & 102 & & & & & & & & & \\
\hline 0 & 0 & & 48 & 6,0 & 3,8 & 5,0 & 0,17 & 0,44 & 0,07 & 5,5 & 75 \\
\hline 5 & 10 & & 51 & 4,9 & 4,1 & 1,8 & 0,26 & 0,37 & & 3,1 & 44 \\
\hline 10 & 20 & & 46 & 4,4 & 4,2 & 0,4 & 0,29 & 0,64 & & 1,8 & 42 \\
\hline Mäski & Brewers' & 46 & & & & & & & & & \\
\hline 0 & 0 & & 19 & 5,0 & 4,0 & 3,9 & 0,84 & 0,21 & 0,06 & 1,5 & 8 \\
\hline 2 & 10 & & 21 & 4,6 & 4,0 & 3,3 & 0,95 & 0,55 & & 0,4 & 9 \\
\hline 4 & 20 & & 20 & 4,4 & 4,2 & 1,2 & 0,19 & 0,65 & & 0,2 & 9 \\
\hline 6 & 30 & & 21 & 4,1 & 4,1 & 1,3 & 0,42 & 0,86 & & 0,2 & 8 \\
\hline
\end{tabular}

\section{Jyväsäilöntä}

Jyväsäilöntäkoe osoitti, että jätemelassi ei estä homeen kasvua jyvissä lainkaan 5-prosenttisena ja vain heikonlaisesti 10-prosenttisenakin väkevyytenä. Jyväkasa on niin löyhä, että homehtuminen tapahtuu pohjaa myöten. Kosteat jyvät myös itävät. Lämpimässä varastossa jyvät alkoivat homehtua jo parissa viikossa, kylmässä hitaammin. Vain silloin kun puumelassiväkevyys oli $10 \%$ ja varasto kylmä jyvät säilyivät kolmen kuukauden ajan homeettomina ja raikkaan hajuisina. Ohra säilyi jyväsäilönnässä, kuten märkäsäilönnässäkin, kauraa paremmin.

Puumelassin vaikutus homeen kasvuun on kaksipuolinen: melassin sisältämät sokerit suosivat hometta, hapot vuorostaan estävät sitä. Vasta suurilla puumelassikonsentraatioilla happojen vaikutus tulee dominoivaksi. Anaerobissa käymisessä (märkäsäilöntä) sen sijaan myös sokerit ovat hyödyllisiä, koska ne ohjaavat käymistä toivottuun suuntaan.

\section{Puumelassi rehuna}

Kokeiden puumelassi oli alkuperältään lähes samaa, mitä on käytetty märehtijäin rehuksi. Se poikkesi niistä lähinnä siinä, että eläimille vastenmielisestä lignosulfonaatista oli ultrasuodatuksella poistettu kaksi kolmasosaa. Tässä muodossa jätemelassia on ehditty kokeilla vasta maittavuuskokeissa ja niissä se on osoittautunut selvästi lignosulfonaattirikasta melassia maittavammaksi. Viikin koetilan lihasonnit ja pässit hyväksyivät sen parissa päivässä. Noin 8 kk:n ikäiset sonnit söivät $10-13 \%$ neutraloitua puumelassia sisältävää väkirehua $8 \mathrm{~kg}, 3-4 \mathrm{kk}$ :n ikäiset vasikat $4 \mathrm{~kg}$ ja pässit $1 \mathrm{~kg}$ eläintä kohden päivässä. Lisärehuna oli heinää vapaasti. Hapanta puumelassia vuorostaan syötettiin puoli vuotiaille hiehoille neljän kilon ja pässeille puolen kilon päiväannoksina puumelassiväkevyyden asteettain noustessa $20 \%$ :iin asti. 
Lisärehuina oli vapaasti heinää ja säilörehua. Koe-eläimet eivät saaneet ripulia eikä muutakaan terveydellistä häiriötä ilmennyt. Myöhempään tutkimusohjelmaan kuuluu tämän uudenlaisen puumelassin rehuarvon määrittäminen kasvatus- ja sulavuuskokeilla.

Puumelassia neutraloidussa muodossa on suunniteltu teollisiin rehuseoksiin juurikasmelassin tilalle. Kielteisiä puolia ovat hankala sekoitusprosessi ja puumelassin vesipitoisuus, mikä alentaa rehuseoksen energia-arvoa. Silloin kun puumelassia lisätään märkäsäilöttävään viljaan, ei kumpaankaan seikkaan tarvitse kiinnittää huomiota, koska märkäsäilönnässä viljaan joudutaan joka tapauksessa sekoittamaan vettä. Kun veden sijasta käytetään puumelassia, saadaan samalla kertaa säilöntäaine, tarvittavaa lisäkosteutta ja myös vähän energiaa. Hapan melassi on lisäksi helpompaa sekoittaa kuin neutraloitu, koska se on vesimäistä nestettä.

Puumelassin happamuus johtuu pääasiassa orgaanisista hapoista eikä niin ollen vaatine ruokinnassa ainakaan suurta neutraloivaa kivennäislisää. Lipeätai ammoniakkiolkea käytettäessä hapan väkirehu saattaisi olla hyväksikin.

Nyt suoritetut kokeet olivat alustavia, laboratoriomittakaavassa suoritettuja ja vaativat lisätutkimuksia, joihin liittyy myös eläinkokeita. Alustavat kokeet suoritettiin tarkoituksella normaalikäytäntöä huonommissa olosuhteissa (lämmin varasto, korkea vesipitoisuus). Märkäsäilöntätulokset vaikuttivat lupaavilta ja kannustavat jatkotutkimuksiin. Myös märän mäskin tilapäissäilytyksessä puumelassista voi hyvinkin olla apua. Jyväsäilöntäkokeen tulos sen sijaan ei suuria lupauksia antanut.

\section{Tiivistelmä}

Lignosulfonaattiköyhdytettyä hapanta sulfiittijäteliemestä valmistettua puumelassia kokeiltiin laboratoriomittakaavassa ohran, kauran ja mäskin märkäsäilöntään sekä ohran ja kauran jyväsäilöntään. Märkäsäilönnässä 10 ja $20 \%$ puumelassia ohran, kauran ja mäskin kuiva-aineesta esti lämpimässä varastossa virhekäymisen. Myös maitohappokäyminen jäi vähäiseksi, koska jo $10 \%$ :n puumelassilisäys alensi $\mathrm{pH}: \mathrm{n}$ alle viiden. Homeen kasvua puumelassi hillitsi vain suurena konsentraationa ja kylmässä varastossa. Sen vuoksi sen käytöstä kostean viljan säilöntään ei ollut sanottavaa hyötyä.

Uudenlainen puumelassi osoittautui runsaasti lignosulfonaatteja sisältävää sulfiittijätelientä maittavammaksi.

\section{KIRJALLISUUSLUETTELO}

Bothast, R. J., Adams, G. H., Hatfield, E. E. \& Lancaster, E. B. 1975. Preservation of high-moisture corn: a microbiological evaluation. J. Dairy Sci. 58: 386-391.

Chang, F. S., Dyer, I. A. \& Johnson, R. J. 1977. Performance of feedlot cattle and rumen microorganisms as influenced by lignosulfonate. J. Anim. Sci. 46: 878-884.

Ettala, E., Ронјanheimo, O. \& Lampila, M. 1972. Eri säilöntäaineilla valmistetut säilörehut lypsykarjan ruokinnassa. Kehittyvä Maatalous 7:1-15. 
Hathaway, H. D. 1973. Potential of lignin sulfonate for liquid feed. AFMa Liquid feed, Proc. 3 rd. Ann. Symp., Arlington, Virginia. Repr. 7 p.

Poutiainen, E., Korhonen, I \& LAMpILA, M. 1973. Eri menetelmillä säilötty ohra lihanautojen rehuna. 1. Lisäaineiden vertailu märkäsäilönnässä. Kehittyvä Maatalous 15: 19-31.

Salo, M.-L., Immonen, M. \& Suomi, K. 1973. Puunjalostusteollisuuden jäteliemipulveri rehuna. Maatal.tiet. Aikak. 45: 284-296.

- - \& Puumala, L. 1978. Nutritive evaluation of spent sulphite liquors. Acta Agric. Scand. 28: $000-000$.

Schmidt, L., Weissbach, F. \& Peters, G. 1978. Harnstoff als Konservierungsmittel bei der Lagerung feuchter Futterstoffe. Arch. Tierernähr. 28: 123-139.

Käsikirjoitus saapunut 1.6.1978 